Original Research

\title{
Pola Asuh Otoritatif dengan Kemandirian Anak Down Syndrome dalam Melakukan Activity Daily Living
}

\author{
Evania Yanasari Ritto ${ }^{*}$, Hartanti $^{1}$, Mary Philia Elisabeth ${ }^{1}$ \\ Fakultas Psikologi Universitas Surabaya, Raya Kalirungkut, Surabaya - Indonesia 60293 \\ *Corresponding author: evaniayanasari@gmail.com
}

\begin{abstract}
The goal of this research was to find out the relation between authoritative parenting and the independence of down syndrome children in doing activity daily living. The participants in this study were 33 parents who had down syndrome children. The sampling technique in this study was conducted by purposive technique. Data collection techniques were carried out by distributing questionnaires for the Parenting Style Dimension Questionnare (PSDQ) and Functional Indpendence Measure for Children (WeeFIM). The results of hypothesis testing using Pearson correlation were found a significantly positive between authoritative parenting and the independence of down syndrome children in performing daily living activities ( $r=0.498<0.05 ; r=$ 0.498). Based on the results of the crosstab, significant associations were found between parents' education, children's age, parents' thoughts about the child's condition, parents' feelings of having down syndrome children, parental treatment to improve children's abilities, and parental treatment of the child's condition with significant associations with independence of down syndrome children in doing activity daily living
\end{abstract}

Keywords : authoritative parenting, independence, down syndrome, activity daily living

Abstrak-Penelitian ini bertujuan untuk mengetahui hubungan antara pola asuh otoritatif dengan kemandirian anak down syndrome dalam melakukan activity daily living. Partisipan dalam penelitian ini sebanyak 33 orang tua yang mempunyai anak down syndrome. Teknik pengambilan sampel dalam penelitian ini dilakukan dengan teknik purposive. Teknik pengambilan data dilakukan dengan membagikan angket Parenting Style Dimension Questionnare (PSDQ) dan Functional Indpendence Measure for Children (WeeFIM). Hasil uji hipotesis menggunakan korelasi pearson dan ditemukan hubungan positif yang signifikan antara pola asuh otoritatif dengan kemandirian anak down syndrome dalam melakukan activity daily living $(r=0,498<0,05 ; r=0,498)$. Berdasarkan hasil crosstab ditemukan asosiasi signifikan antara pendidikan akhir orang tua, usia anak, pikiran orang tua mengenai kondisi anak, perasaan orang tua memiliki anak down syndrome, perlakuan orang tua untuk meningkatkan kemampuan anak, dan perlakuan orang tua terhadap kondisi anak memiliki asosiasi signifikan dengan kemandirian anak down syndrome dalam melakukan activity daily living.

Kata kunci : pola asuh otoritatif, kemandirian, down syndrome, activity daily living

\section{PENDAHULUAN}

Anak down syndrome memiliki karakter fenotip umum yaitu memiliki karakter otot yang lemah yang dikenal dengan hypotonia, kemiringan pada atas mata, dan lipatan tunggal di seluruh pusat dua telapak tangan (Jones, 2014). Terdapat tiga faktor umum pada anak down syndrome yang memengaruhi fungsi neuromuscular dan pergerakan pada fungsi-fungsi tertentu, di antaranya kapasitas aerobic yang lebih rendah, denyut jantung yang lebih rendah, serta penurunan kekuatan otot atau lemahnya otot yang disebut dengan kondisi hypotonia.

Anak down syndrome memiliki beberapa karakter fisik seperti, tangan yang kecil, jari yang pendek, kesulitan dalam menggenggam dan mengkoordinasi gerakan otot kecil , sehingga mengalami kesulitan memasang kancing baju dan menulis (Jones, 2014). Secara umum perkembangan motorik kasar dan halus anak down syndrome berada pada urutan yang sama dengan anak pada umumnya, tetapi pada tingkat yang lebih lambat dibandingkan dengan anak pada umumnya (Jones, 2014). Seperti halnya anak down syndrome yang baru bisa berdiri ketika berusia 24 bulan, hal ini lebih lambat dibandingkan dengan anak pada umumnya (Hazmi, Tirtayasa, \& Irfan, 2014). Bruni mengatakan bahwa lemahnya kemampuan motorik kasar dan halus pada anak down syndrome membuat mereka mengalami kesulitan dalam melakukan kegiatan sehari-hari (Asih, 2009).

Activity Daily Living adalah keterampilan dasar dan tugas okupasional yang harus dimiliki seseorang untuk merawat dirinya secara mandiri yang dikerjakan seseorang sehari-harinya dengan tujuan untuk memenuhi/berhubungan dengan perannya sebagai pribadi dalam keluarga dan masyarakat (Sugiarto, 2005). Menurut Howard, Williams dan Lepper, 2011; Caleb 
dan Cull, 2000; McCaleb dan Edgil, 1994 (dalam Kılıçgün \& Kılıçkaya, 2014) peningkatan dan pengembangan keterampilan merawat diri anak merupakan langkah terbesar seorang anak untuk menjadi mandiri dan percaya diri, sehingga peningkatan dan pengembangan kemampuan merawat diri anak menjadi bagian yang penting dalam konteks keterampilan untuk hidup mandiri. Terdapat tiga gaya pengasuhan orang tua menurut Baumrind yaitu otoritatif, otoriter, dan permisif, kemudian pada tahun 1983 Maccoby dan Martin membagi pola asuh permisif menjadi dua yaitu permisif indulgent dan permisif indifferent (Santrock, 2002). Menurut Baumrind orang tua yang menerapakan pola asuh otoritatif memungkinkan anak untuk dapat percaya diri, mandiri, dan bertanggung jawab secara sosial. Orang tua dengan gaya pengasuhan ini memiliki karakter yang tinggi dalam responsiveness (kehangatan atau penerimaan) serta demandingness (kontrol atau tuntutan) (Steinberg,2002).

Hasil penelitian yang dilakukan oleh Philips, Conners, dan Smith (2017) menemukan bahwa pola asuh ibu dengan anak down syndrome lebih banyak menggunakan pola asuh permisif dari pada pola asuh otoritatif. Mereka beranggapan dengan memberikan kepada anak apa yang diinginkan untuk sementara waktu akan menghilangkan perilaku bermasalah pada anak secara sementara, anggapan para ibu ini dapat meredakan stress yang dimiliki akan perilaku buruk anak mereka. Hasil penelitian Herlina (2013) ditemukan sebagian besar keluarga dengan pola asuh otoritatif mempunyai 29 anak mandiri (76,3\%) dan 9 anak tidak mandiri $(23,7 \%)$, pola asuh permisif memiliki 25 anak mandiri (54,3\%) dan 21 anak tidak mandiri $(45,7 \%)$, sementara keluarga dengan pola asuh otoriter mempunyai 9 anak mandiri $(39,1 \%)$ dan 14 anak tidak mandiri $(60,9 \%)$. Hasil penelitian Putra (2016) Orang tua dengan gaya pengasuhan otoritatif yaitu 28 responden orang tua $(63,6 \%)$ mempuyai 6 anak kurang otonom (13,6\%) dan 22 anak otonom (50\%) dalam self-help skilss atau kemampuan rawat diri, sebaliknya, pola asuh otoriter sebanyak 16 orang tua $(36,4 \%)$ mempunyai 11 anak kurang otonom (25\%) dan 5 anak otonom (11,4\%) dalam melakukan self-help skills atau kemampuan rawat diri. Berbeda dengan penelitian Ramawati, Allenidekania, dan Besral (2012) tidak ditemukan hubungan bermakna antara pola asuh orang tua dengan kemandirian anak tunagrahita dalam perawatan diri. Berdasarkan beberapa hasil penelitian di atas, peneliti melihat pola asuh otoritatif masih memiliki anak yang tidak mandiri dan mandiri dalam melakukan aktivitas sehari-hari untuk merawat diri ,sedangkan menurut Baumrind pola asuh otoritatif dapat mendorong kemandirian anak (Santrock, 2002). Dari sini peneliti melihat peneliti melihat masih perlu dibutuhkan penelitian lebih lanjut mengenai hubungan antara pola asuh otoritatif dengan kemandirian anak down syndrome dalam melakukan activity daily living.

\section{METODE}

Penelitian ini menggunakan metode kuantitatif. Subjek dalam penelitian ini memiliki kriteria tertentu yaitu, orang tua yang memiliki anak down syndrome yang duduk di kelas 1-6 SD yang bersekolah di sekolah luar biasa atau sekolah inklusi. Penelitian ini menggunakan teknik pengambilan sampel dengan purposive. Terdapat dua macam angket dalam penelitian ini. Pertama, angket terbuka berisi nama orang tua, pendidikan terakhir orang tua, nama anak, usia anak, jenis kelamin anak, pendidikan anak, jenis kebutuhan anak, riwayat medis anak, jenis terapi yang dijalani serta berapa lama, kegiatan yang anak sudah mandiri, kegiatan yang anak masih memerlukan bantuan, pikiran orang tua memiliki anak down syndrome, perasaan orang tua, perlakuan orang tua untuk meningkatkan kemampuan anak, perlakuan orang tua dengan kondisi anak, sifat yang dibanggakan dari anak, dan hal yang dikeluhkan dari kondisi anak. Kedua, angket tertutup berisi pernyataan yang harus dipilih subjek berdasarkan variabelvariabel berikut.

Peneliti mengambil data pola asuh otoriatif dengan menggunakan kuisioner Parenting Style and Demension Quistionare (PSDQ) yang dibuat oleh (Hart, Newel, \& Olsen, 2003). Kuisioner ini terdiri dari 62 pertanyaan untuk mengukur intensitas pola asuh otoritatif, 
otoriter, dan permisif. Peneliti hanya menggunakan 27 pertanyaan untuk mengukur intensitas pola asuh otoritatif. Skala yang digunakan dalam penelitian ini ialah skala likert yang terdiri dari empat jawaban yaitu tidak pernah, kadang-kadang, sering, dan selalu.

Peneliti mengambil data kemandirian dalam melakukan activity daily living dengan menggunakan Functional Independence Measure for Children (WeeFIM) yang telah dielisitasi. Peneliti menambahkan rincian aktivitas dan pilihan jawaban skor 1 yaitu anak sama sekali tidak bisa melakukan, skor 2 anak membutuhkan bantuan dengan jumlah banyak, skor 3 anak membutuhkan bantuan dengan jumlah sedang, skor 4 anak membutuhkan bantuan dengan jumlah sedikit, dan skor 5 anak tidak membutuhkan bantuan sama sekali.

\section{HASIL}

Tabel 1

Hasil Uji Validitas dan Reliabilitas Angket PSDQ

\begin{tabular}{|c|c|c|c|c|}
\hline Aspek & Butir Asli & Butir Gugur & $\begin{array}{l}\text { Validitas Corrested } \\
\text { item-total correlation }\end{array}$ & $\begin{array}{l}\text { Reliabilitas } \\
\text { Alpha Cronbach }\end{array}$ \\
\hline Connection & $\begin{array}{l}1,2,3,4,5,6 \\
7,8,9,10,26\end{array}$ & - & $0,410-0,751$ & 0,887 \\
\hline Regulation & $\begin{array}{l}11,12,13,14 \\
15,16,17\end{array}$ & - & $0,524-0,711$ & 0,868 \\
\hline Autonomy & $\begin{array}{l}18,19,20,21 \\
27\end{array}$ & 27 & $0,689-0,773$ & 0,861 \\
\hline Good Natured & $22,23,24,25$ & 23 & $0,417-0,723$ & 0,707 \\
\hline
\end{tabular}

Dari tabel 1 dilihat bahwa butir nomor 27 memiliki nilai CITC $-0,43 \leq 0,3$, hal ini juga sama dengan butir yang nomor 23 memiliki nilai CITC $0.214 \leq 0,3$. Kedua butir ini digugurkan dikarenakan memiliki nilai CITC yang kurang dari 0,3 dan dapat menaikan alpha cronbach.

Tabel 2

Hasil Uji Validitas dan Reliabilitas Angket WeeFIM

\begin{tabular}{|c|c|c|c|c|}
\hline Aspek & Butir Asli & $\begin{array}{l}\text { Butir } \\
\text { Gugur }\end{array}$ & $\begin{array}{l}\text { Validitas } \\
\text { Corrected item- } \\
\text { total }\end{array}$ & $\begin{array}{l}\text { Reliabilitas } \\
\text { Alpha Cronbach }\end{array}$ \\
\hline Self-care & $\begin{array}{l}1 \mathrm{~A}, 1 \mathrm{~B}, 1 \mathrm{C}, 1 \mathrm{D}, 1 \mathrm{E}, 1 \mathrm{~F}, 1 \mathrm{G}, \\
2 \mathrm{~A}, 2 \mathrm{~B}, 2 \mathrm{C}, 2 \mathrm{D}, 3 \mathrm{~A}, 3 \mathrm{~B}, 3 \mathrm{C} \\
3 \mathrm{D}, 3 \mathrm{E}, 3 \mathrm{~F}, 4 \mathrm{~A}, 4 \mathrm{~B}, 4 \mathrm{C}, 5 \mathrm{~A}, 5 \mathrm{~B}, \\
5 \mathrm{C}, 5 \mathrm{D}, 5 \mathrm{E}, 5 \mathrm{~F}, 5 \mathrm{G}, 6 \mathrm{~A}, 6 \mathrm{~B}, 6 \mathrm{C} \\
6 \mathrm{D}, 6 \mathrm{E}, 6 \mathrm{~F}, 7 \mathrm{~A}, 7 \mathrm{~B}, 7 \mathrm{C}, 7 \mathrm{D}, 7 \mathrm{E}, \\
7 \mathrm{~F}, 10 \mathrm{~A}, 10 \mathrm{~B}, 10 \mathrm{C}, 10 \mathrm{D}\end{array}$ & & $0,320-0,785$ & 0,967 \\
\hline Mobility & $8,9 A, 9 B$ & & $0,805-0,893$ & 0,931 \\
\hline Cognition & $\begin{array}{l}12 \mathrm{~A}, 12 \mathrm{~B}, 12 \mathrm{C}, 13,14 \mathrm{~A}, 14 \mathrm{~B}, \\
14 \mathrm{C}, 15,16 \mathrm{~A}, 16 \mathrm{~B}, 16 \mathrm{C}, 16 \mathrm{D}\end{array}$ & & $0,424-0,700$ & 0.820 \\
\hline $\begin{array}{l}\text { Vokasional } \\
\text { Jumlah }\end{array}$ & $\begin{array}{l}11 \mathrm{~A}, 11 \mathrm{~B}, 11 \mathrm{C}, 11 \mathrm{D}, 11 \mathrm{E}, 11 \mathrm{~F} \\
63\end{array}$ & $\begin{array}{l}11 \mathrm{~F} \\
1\end{array}$ & $0,414-0,807$ & 0,849 \\
\hline
\end{tabular}

Dari Tabel 2 Butir 11F digugurkan karena memiliki nilai CITC yaitu 0.097, apabila butir $11 \mathrm{~F}$ dihapus menyebabkan alpha cronbach menjadi naik yang awalnya 0.773 menjadi 0.849 , 
hal ini dapat dilihat pada output SPSS yaitu cronbach's alpha if item deleted.

Hipotesis yang dalam penilitan ini adalah terdapat hubungan positif antara pola asuh otoritatif dengan kemandirian anak down syndrome dalam melakukan activity daily living. Hasil analisis pearson correlation diperoleh nilai $r$ sebesar 0.498 dengan nilai $p 0.003$ artinya hipotesis diterima.

Tabel 3

Ringkasan Tabulasi Silang Antara Data Angket Terbuka dan Data Demografis Dengan Kemandirian Anak Down Syndrome Dalam Melakukan Activity Daily Living

\begin{tabular}{|c|c|c|c|}
\hline Data Demografis/Angket Terbuka & $\begin{array}{c}\text { Pearson } \\
\text { Chi- Square }\end{array}$ & Sta & tus \\
\hline 1. Pendidikan akhir orang tua & 0.000 & $\begin{array}{l}\text { Terdapat } \\
\text { signifikan }\end{array}$ & asosiasi \\
\hline $\begin{array}{l}\text { 2. Pikiran orang tua mengenai kondisi } \\
\text { Anak }\end{array}$ & 0.004 & $\begin{array}{l}\text { Terdapat } \\
\text { signifikan }\end{array}$ & asosiasi \\
\hline $\begin{array}{l}\text { 3. Perasaan orang tua memiliki anak } \\
\text { down syndrome }\end{array}$ & 0.000 & $\begin{array}{l}\text { Terdapat } \\
\text { signifikan }\end{array}$ & asosiasi \\
\hline $\begin{array}{l}\text { 4. Perlakuan orang tua untuk } \\
\text { meningkatkan kemampuan anak }\end{array}$ & 0.000 & $\begin{array}{l}\text { Terdapat } \\
\text { signifikan }\end{array}$ & asosiasi \\
\hline $\begin{array}{l}\text { 5. Perlakuan orang tua dengan } \\
\text { kondisi anak }\end{array}$ & 0.008 & $\begin{array}{l}\text { Terdapat } \\
\text { signifikan }\end{array}$ & asosiasi \\
\hline
\end{tabular}

Tabel 3 menunjukkan bahwa terdapat asosiasi signifikan antara pendidikan akhir orang tua, umur anak, pikiran orang tua, perasaan orang tua, perlakuan orang tua untuk meningkatkan kemampuan anak, dan perlakuan orang tua dengan kondisi anak.

\section{BAHASAN}

Berdasarkan hasil uji hipotesis dapat ditemukan bahwa pola asuh otoritatif memiliki hubungan yang tergolong sedang dengan kemandirian anak down syndrome dalam melakukan $\operatorname{ADL}(p=0.003 \leq 0,05 ; r=0,498)$, yang menandakan semakin tinggi skor pola asuh otoritatif yang diterapkan maka semakin tinggi pula skor kemandirian anak down syndrome dalam melakukan ADL, sebaliknya apabila semakin rendah tingkat pola asuh otoritatif yang diterapkan oleh orang tua maka semakin rendah pula kemandirian anak down syndrome dalam melakukan ADL. Dalam penelitian ini juga ditemukan nilai $R^{2}=0,498^{2}=0.2480$ yang berarti pola asuh otoritatif memberikan sumbangan terhadap kemandirian anak down syndrome dalam melakukan activity daily living sebesar 0.2480 atau $24,80 \%$. Hasil penelitian ini mendukung hasil penelitian terdahulu yang dilakukan oleh Putra (2016) dan Herlina (2013) serta sesuai dengan teori pola asuh Baumrind (dalam Santrock, 2002). Pola asuh otoritatif merupakan pola asuh yang mendukung dan berdampak dengan kemandirian anak tetapi masih menetapkan batas-batas dan pengendalian atas tindakan-tindakan mereka.

Pada penelitian ini perilaku-perliaku orang tua dalam menerapkan pola asuh otoritatif, diantaranya adalah perilaku orang tua yang memberikan pujian kepada anak ketika anak dapat membuka celana atau rok dengan benar, perilaku orang tua yang tanggap dengan kesusahan anak, seperti orang tua mencontohkan pada anak cara memasang kancing baju pada anak secara berulang-ulang ketika mengalami kesusahan. Perilaku pola asuh otoritatif lain adalah memberikan anak kesempatan dan pilihan pada anak untuk mencoba hal- hal yang baru atau hal-hal yang belum ia bisa lakukan, seperti perilaku orang tua yang membiarkan anaknya terlebih dahulu mencoba dengan usahanya sendiri untuk mengancing baju. 


\section{SIMPULAN}

Terdapat beberapa simpulan dalam penelitian ini. Pertama, terdapat hubungan yang positif signifikan antara pola asuh otoriTatif dengan kemandirian anak down syndrome dalam melakukan activity daily living. Hal ini berarti semakin tinggi pola asuh otoritatif yang diterapkan oleh orang tua maka semakin tinggi kemandirian anak down syndrome dalam melakukan activity daily living, begitu pun sebaliknya. Kedua, ditinjau dari kategori norma ideal, dalam penelitian ini tingkat penerapan pola asuh otoritatif orang tua tergolong sangat tinggi dan kemandirian anak down syndrome dalam melakukan activity daily living tergolong tinggi. Ketiga, berdasarkan hasil tabulasi silang ditemukan bahwa usia anak, pikiran orang tua mengenai kondisi anak, perasaan orang tua memiliki anak down syndrome, perlakuan orang tua untuk meningkatkan kemampuan anak, dan perlakuan orang tua terhadap kondisi anak memiliki asosiasi signifikan dengan kemandirian anak down syndrome dalam melakukan activity daily living.

\section{PUSTAKA ACUAN}

Asih, DS 2009, Peran pemberian program oral eating-drinking care plan (OEDCP) terhadap self help eating-drinking (SHED) anak down syndrome, Tesis, Fakultas Psikologi Universitas Surabaya.

Hart, CH, Newell, LD \& Olsen, SF 2003, Parenting skills and social-communicative competence in childhood, Lawrance Erlbaulm Associates, Mahwah, NJ.

Hazmi, DF, Tirtayasa, K \& Irfan, M 2014. 'The combination of neuro developmental treatment and sensory intergaration is better than just neuro developmental treatment to improve the balance of stand in children with down syndrome', Sport and Fitness Jorunal, 56-71.

Herlina 2013, Hubungan antara pola asuh keluarga dengan kemandirian perawatan diri anak usia sekolah di Kelurahan Cisalak Pasar Kecamatan Simanggis Kota Depok, Tesis, Fakultas Imu Keperawatan Universitas Indonesia, Jakarta.

Jones, S 2014, Effect of motor skills and cognition on activites of daily living in children with down syndrome, Texas Christian University, Texas.

Putra, IK 2016, 'Correlations between parenting style and self-help skills in preschool children (3-6 Years Old)', American Scientific Research Journal for Engineering, Technology, and Sciences (ASRJETS) 24,(1) , 10-15.

Ramawati, D, Allenidekania, Besral 2012, 'Kemampuan perawatan diri anak tunagrahita berdasarkan faktor internal dan eksternal anak, Jurnal Keperawatan Indonesia, 15(2), 89-96.

Santrock, JW 2002, Life span development (perkembangan masa hidup), 5th ed., J. Damanika \& A. Chusari, Pengalih bhs, Erlangga, Jakarta.

Sugiarto, A 2005, Penilaian keseimbangan dengan aktivitas kehidupan sehari-hari pada lansia di Panti Werdha Pelkris Elim Semarang dengan menggunakan Berg Balance Scale dan Indeks Barthel, Fakultas Kedokteran Universitas Diponegoro, Semarang.

\section{BIBLIOGRAFI}

Kılıçgüna, MY \& Kılıçkayab, A 2014, 'Predictor effect of parental authority on the children's selfcare skills', The European Proceedings of Social \& Behavioural Sciences , 60-68.

Phillips, BA, Conners, F \& Smith, ME 2017, 'Parenting children with down syndrome: An analysis of parenting styles, parenting dimensions, and parental stress', Reseacrh in Developmental Disablities, 9-19. 